\title{
Thibault Lachat, Auguste Viatte et les échanges culturels francophones: un intellectuel à la croisée des champs culturels français et francophones
}

\section{Maria Chiara Gnocchi}

\section{(2) OpenEdition Journals}

Édition électronique

URL : https://journals.openedition.org/studifrancesi/26903

DOI : 10.4000/studifrancesi.26903

ISSN : 2427-5856

Éditeur

Rosenberg \& Sellier

\section{Édition imprimée}

Date de publication : 1 avril 2007

Pagination : 218

ISSN : 0039-2944

\section{Référence électronique}

Maria Chiara Gnocchi, «Thibault Lachat, Auguste Viatte et les échanges culturels francophones: un intellectuel à la croisée des champs culturels français et francophones », Studi Francesi [En ligne], 151 (LI I I) | 2007, mis en ligne le 30 novembre 2015, consulté le 23 novembre 2021. URL : http://

journals.openedition.org/studifrancesi/26903; DOI : https://doi.org/10.4000/studifrancesi.26903

Ce document a été généré automatiquement le 23 novembre 2021.

\section{c)}

Studi Francesi è distribuita con Licenza Creative Commons Attribuzione - Non commerciale - Non opere derivate 4.0 Internazionale. 


\title{
Thibault Lachat, Auguste Viatte et les échanges culturels francophones: un intellectuel à la croisée des champs culturels français et francophones
}

\author{
Maria Chiara Gnocchi
}

\section{RÉFÉRENCE}

THIBAULT LACHAT, Auguste Viatte et les échanges culturels francophones: un intellectuel à la croisée des champs culturels français et francophones, in Jérôme Meizoz (a cura di), La circulation internationale des littératures, «Études de Lettres», n. 1-2, 2006, pp. 293-311.

1 Lorsqu'on s'occupe d'études francophones, on a tendance à attribuer à toute impulsion impérialiste un mépris plus ou moins caché pour les populations assujetties, et à associer, inversement, l'ouverture aux cultures «autres» à une foi progressiste et indépendantiste. Tel est souvent le cas, en effet, mais non systématiquement. L'article consacré à Auguste Viatte que Thibault Lachat a publié dans le dernier numéro d'«Études de Lettres» est là pour nous le prouver (Thibault Lachat est l'auteur d'un mémoire de licence présenté en 2004 à l'Université de Fribourg, centré précisément sur Auguste Viatte et la francophonie au temps de la décolonisation).

2 Né en 1901, Auguste Viatte est professeur de français; imbu de culture française, nourri par un esprit colonialiste et paternaliste inspiré de Lyautey (dont il entend suivre l'«idéal»), il ne peut concevoir de gloire nationale sans le complément «nécessaire» du rayonnement impérial, qui sert le prestige de la nation encore plus que ses exigences pragmatico-économiques. Viatte est convaincu que la force de la France réside dans l'ensemble de son Empire et que chaque territoire sous domination mérite l'attention des métropolitains. Il confie, à ce propos, à son journal: «Éclairer la France sur ce qui se passe au dehors. Telle semble ma mission» (Journaux de voyage, 1931); âgé de trente ans 
seulement, le professeur pressent déjà le rôle de médiateur qu'il aura effectivement, dans les années à venir, entre les champs culturels français et francophones. Les origines de Viatte (alsaciennes par sa mère et jurassiennes par son père) ne sont sans doute pas étrangères à l'attention qu'il porte à la francophonie; ce qui est certain c'est qu'il ne cesse d'insister, dans tous ses écrits, sur l'importance de tous les territoires attachés à la France. Même les petites îles apparemment inutiles ont à ses yeux «un mérite, par le seul fait qu'elles existent: celui d'affirmer notre présence» (d'après un article de journal).

3 L'intérêt que Viatte porte à l'«ailleurs» le conduit à considérer d'une manière inédite la culture française: dans un ouvrage publié en 1935, il invite «à ne plus voir comme unique centre de développement culturel la place parisienne». Bien que linguistiquement et culturellement liée à la France, la périphérie a aussi, désormais, une personnalité propre, sur laquelle il convient de se pencher. Ce n'est pas tout: de manière absolument novatrice, Viatte encourage un métissage culturel qui, «loin de l'altérer, vient soutenir et enrichir la culture française»: universelle, celle-ci conviendrait en effet à l'expression de toutes les populations. Dans un article publié en 1941, alors que la France métropolitaine est divisée, Viatte emploie le terme francophone, jusqu'alors pratiquement inusité, et élabore l'une des premières répartitions de ce «monde» qu'une même langue relie, et qu'il voudrait solidaire. Nommé professeur à l'Université Laval de Québec, puis à l'Université de Nancy et à l'École polytechnique de Zurich, Viatte fait figure de référence, pendant de longues années, en matière de littérature française ainsi que de médiateur entre la France et le reste du monde d'expression française. Parmi les œuvres qu'il consacre aux littératures francophones dès les années cinquante, on retiendra Histoire littéraire de l'Amérique française (1954), La Francophonie (1969), Histoire comparée des littératures francophones (1980). 